\title{
Psychological State of Working and Non-Working Woman's Child
}

\author{
Chaitali R. Tailor ${ }^{1}$
}

Keywords: Mental health, Employed, Unemployed, Male, Female, Ahmedabad

Environmental factors play a vital role in the growth and development of a child. The contribution of Manu Smriti Granth towards Indian culture holds the importance, that believes man and woman to be two important pillars of society and owes the responsibility being parents. It is saying in Gujarati that,

\section{એક આચાર્ય દશ ઉપાધ્યાઓ કરતાં શ્રેષ્ટ છે. એક પિતા સો આચાર્યો કરતાં શ્રેષ્ટ છે. પરંતુ એક માતા હજાર પિતાઓ કરતાં શ્રેષ્ઠત્તમ છે.}

This says that parent has a superior role to play than to a teacher in child's development. To stand with the time, women are now becoming career oriented. Cultural nourishment is now an alarming concern as both man and woman remains occupied with job/business.

According to Vandana Desai (1978), due to socio-political make up of our country, every educated or uneducated girl is necessitated to earn. The total count of working women in India in all sectors is more than 10 cores. Apparently, both parent being working are likely to devote less of time in the upbringing of their child which affects the mental and personality development of a child which disturbs the mental health of a child.

Singh (1996) in his study says that a child of a working women tends to be free, open minded, self reliant, independent, brave, flexible and easy to gel up kind.

Rana \& Carr (1998) studies say that compared to boys, daughter of a working mothers see their parents as less hostile, less authoritarian and more loving.

Bandura and Walter (1963) says that kid who is deprived of their parent's love and attention are more aggressive and rebellious in nature.

\footnotetext{
${ }^{1}$ MA, B. Ed, Psychology, PhD Student, Department Of Psychology, Veer Narmad South Gujarat University
}

(C) 2015 I C Tailor; licensee IJIP. This is an Open Access Research distributed under the terms of the Creative Commons Attribution License (http://creativecommons.org/licenses/by/2.0), which permits unrestricted use, distribution, and reproduction in any Medium, provided the original work is properly cited. 
At last, the responsibility of shaping the future of an adolescent lies to parents. When varied situation gets messed up and affect each other, the concern is to see what outcomes these situation bears. Again, in near future when every woman would be working, how will she ensure that their child is not depressed? How a working women will see for the mental well being and overall personality of their child? These questions needs immediate answer in recent times.

\section{Working Women means -}

Working Women are the ones who earns salary/wages outside the home alongwith the care taking of their child and the household chores.

\section{-William Bauer - 2006}

Also, "Women working in Government, Semi-Government or Private sector and drawing salary on lump sum or daily basis."

-Aitin Saadat - 2009

\section{Non-Working Women means -}

"Women who does all housework and shoulders all the social responsibilities without any expectation of monetary returns."

A study done by Navbharat Times in 1963 states that, working women falls the expectation in getting sympathy and support from their family.

This proves that inspite playing various roles in the family, women are subjected to psychological questions.

A study on the effects of the Mother's employment on child includes research works of Jonas \& Bride (1980), Rob \& Raven (1982), Baal (1988), Vijaylaxmi (1989), Singh(1991) Singh (1996), Joshi \& Juyal (1997), Gulati (1998),

All these studies are made in relation to the impact of mother's employment on conditions of the family, the upbringing of an adolescent and its behavioral development.

\section{ADOLESCENCE MEANS}

A psychologist named, A.T. Jersild has stated that, "Adolescent is that phase of life, in which young girls and boys mentally, aggressively, physically and socially takes transit from late childhood to early adulthood. 


\section{Problems of the Adolescence}

Any kind of change brings with it the associated problems. Adolescence is the age of transit from late childhood to early adulthood. Crow \& Crow named psychologist has listed the problems of adolescent as below -

1. Family relations of the teenager and problems arising out of that.

2. Problems arising out of the inner conflicts faced by them.

3. Problems regarding consciousness of the outward physical appearance.

4. Problems related to intellect and aptitude.

5. Problems in selection of Career and Business.

6. Problems adjusting with the opposite gender.

\section{MENTAL HEALTH MEANS}

The question of mental well-being is the most burning question of the modern times. If a person really wants to be happy and successful, he will have to learn the art of staying healthy. A mentally healthy person is able to know and understand his own self. He is able to differentiate between the right and the wrong before starting to do anything and forecast the future results. He stays confident and constantly feels that he holds a position in the world. Many sees themselves as a weak, and take blames for all the failures in all the tasks. They keeps on checking the work after completion, for example-

-Checking on with the count of money repeatedly, -Frequent checks with the wallet or money in the pocket, -Locks the room, but more than double-checks the lock by pulling on it.

Such acts prove that such persons lack confidence in their own self and their work done. Weakness, Inferiority complex, unnecessary tensions or scares, etc. show the ill-being of the mental health.

Well, the world of psychological health is quite vast. It can be that the whole world goes round the health. Mental health is at the center of the overall health square. It holds the foremost position. The four pillars of health are also dependent on it. Its figure can be as displayed below 


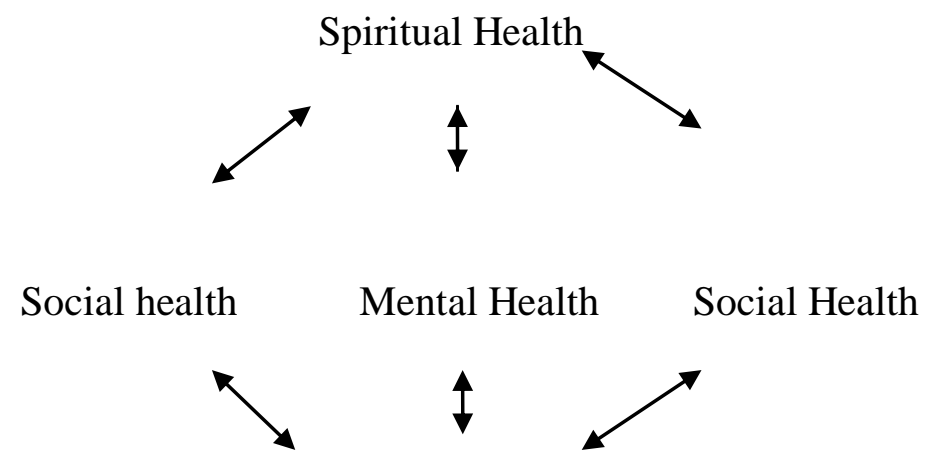

Physical health

Everyone has to pass through three stages, (1) Ignorance (2) Opposition (3) Acceptance. The person, who is able to foresee a long way ahead of its present, surely becomes a prey to misunderstandings. Meaning by, let opposition and suppression come by. These hindrances will be crossed over if we stand confident and unmoved. This proves that necessity shapes the one's being. Has it ever happened that, you were deprived of something that you really needed? Or you have not got it?

\section{Active Trusts in the field of Mental Health}

In America's many of the top rated schools have the syllabus of CATCHPHRASE - which says that with early treatment, many mental sicknesses can be ceased. Other than this, these are other trusts in America working for the psychological state.

1. National Institute of Mental Health.

2. National School of Mental Health.

3. National Committee for anti mental illness

4. B.M. Institute of Mental health

5. Yog and Self-development Academy

6. Mental Health Education and Research Trust.

\section{Symptoms of mentally healthy persons}

Dr. A. M. Patel and others (2003) voted for the following symptoms seen in the mentally healthy persons -

1. Physical Health

2. Tolerance

3. Determination

4. Responsibility

5. Socialite 
6. Punctuality

7. Self-esteem

8. Self-confidence

9. Trust on others

10. Adaptability

11. Strong character

12. Love for independence

13. Non-reliance on Self defence.

14. Emotional Quotient

15. Vision of life

Factors affecting the mental health

As per views of Dr. M. Panchal (1977), the mental health is affected by two broad factors -

\section{Mental Health}

$\begin{array}{lc}\text { Lineage } & \text { Atmosphere } \\ \text { - Physical state } & \text { - Home } \\ \text { - Intelligence } & \text { - School } \\ \text { - Business efficiency } & \\ \text { - Character } & \end{array}$

\section{Matters endangering Mental Well-being}

To stay healthy mentally means to "stay happy". Psychological health and happiness are deeprouted. Happiness is an encouraging sparkle. Until people do the things that make them happy, mental well-being is not in danger. But when there is conflict, mental health will be at stake. Factors that put mental health in danger are as follows -

1. Stress

2. Suppression

3. Aggressiveness

4. Lake of physical health

5. Deficiency of the social quotient

6. Instinctual Drive

7. Dissatisfaction of needs 


\section{Psychological State of Working and Non-Working Woman's Child}

8. Depression \& Struggle

9. Lack of proper development in childhood

10. Slow language development, autism, financial conditions, etc.

\section{Ways to maintain mental Health}

1. For speedy development of an adolescent, they should be made aware of the changes occurring in their body. This will help cope up with the changing scenario and saves them from disappointment.

2. Inherent energy in an adolescent to be evolved and accepted to best fit the socially accepted way of life.

3. Make them know the real world which will release the tension and stress.

4. At this stage proper diet nourishment is necessary. They should be motivated to stay active by doing exercise and enrolling in outdoor activities.

5. Advocate co-education to alleviate opposite gender anxiety and skeptics.

6. Provide them required opportunities to express their feelings and thoughts.

7. Making self desire strong enough.

8. Changing the surrounding environment.

9. Establishment of varied institutions for their better development.

10. Examining one's own conscious thoughts and feelings.

11. Should cultivate interest and likings.

12. An adolescent should make close friends with whom problems can be shared and sorted out.

13. An early decision is a quality that they should learn to adapt to the fast changing times.

Following the above said ways, if we struggle the sufferings of the world, then mental illness can be cured easily.

The science concerning mental health can be applied in any field. There is a saying,

\section{"Prevention is better than cure."}

It is better not to fall sick at first place than to be cured swallowing medicinal drugs. Also, it is better to try to keep a bad thing from happening than it is to fix the bad thing once it has happened. Preventing child's mental health deteriorating and promoting good mental health is a much better approach than dealing with later difficulties. Prevention is the key.

\section{REFERENCES:}

1. Vandana Desai (1978): A study on role conflict of a working women, Psychology Department, VNSGU, Surat

2. Chandulal Solarka (1994): A child and Parent, first Paper, Ahmedabad. 
3. Premila Rajendra Bhatt (2000): Educational Psychologist, Gajanand Library, Surat

4. Singh U. (1996): A Study of some personality characteristic of school adolescents in relation to their mother's employment, Indian psychology review, Vol-46, No-9-10, Page No.173-176.

5. Rana and Kaar P. (1998): Sex and occupation as determinants of parents - child relationship, Pranchi Journal of Psycho-cultural dimensions, April, Val-4, No.1, Page 49-54.

6. Bandura A and Walter R. H. (1963): Social learning and personality development, New York - Holt Rinehart and Winston.

7. Joshi R and Juyal S.L. (1997): A study of adjustment, mental health \& Family relationship of children of working and non-working mother, A paper presentation in 2nd Asian \& 3rd IAAP International conference Hardwar.

8. Crow \& Crow: Education psychology, Eurasia publishing house, New Delhi.

9. Swami Achilananda (1995): ,Mental health\& Hindu Psychology.

10. Aitin Saadat (2009): Compare efficiency with working and non-working woman, Europe Journal of scientific Research, Vol- 32, Issue 4, and Page No.533.

11. Vandana Desai (1978): 'Role related struggles in working women', Psychology Department, Veer Narman South Gujarat University, Surat

12. Premila Rajendra Bhatt (2000): Educational Psychology, Gajanan Publications, Surat

13. Dr. Motibhai M. Patel Et al. (2003-04): 'Adhyata, swaroop ane vikaas, dwitiya avrutti', B. S. Shah Publications, Ahmedabad

14. Vedant Desai (1978): Vyavasayik striyoma bhumika-sangharsh abhyas', Psychology Dept., Veer Narmad South Gujarat University

15. Chandulal Solarka (1994): 'Balak ane ma-baap', Pratham avrutti, Ahmedabad

16. Premila Rajendra Bhatt (2000): Shaikshanik Manovigyaan, Gajanan Pustakalay, Ahmedabad 